\title{
Fatty acid composition of Heterorhabditis sp. during storage
}

\author{
Paul F.L. Fitters ${ }^{\mathrm{a}, *}$, Mavji N. Patel ${ }^{\mathrm{b}}$, Christine T. Griffin ${ }^{\mathrm{a}}$, Denis J. Wright ${ }^{\mathrm{b}}$ \\ a Department of Biology, National University of Ireland Maynooth (NUIM), Maynooth, Co. Kildare, Ireland \\ ${ }^{\mathrm{b}}$ Department of Biology, Imperial College of Science, Technology and Medicine, Silwood Park, Ascot, Berkshire SL5 7PY, UK
}

Received 8 March 1999; received in revised form 4 June 1999; accepted 8 June 1999

\begin{abstract}
The fatty acid composition of three North West European isolates of Heterorhabditis sp. from different geographical origins, UK211 (England), HF85 (The Netherlands) and EU17 (Estonia) was assessed directly after harvest and, for UK211 and HF85, after 5 weeks storage in water at $20^{\circ} \mathrm{C}$. Lipid represented $34-43 \%$ of the dry weight of fresh nematodes. Of this, neutral lipid (NL) comprised from $70 \%$ (HF85) to over $90 \%$ (UK211, EU17). The fatty acid patterns were similar between the three isolates. Oleic (C18:1n-9), palmitic (C16:0), and linoleic (C18:2n-6) acid predominated with 51, 13 and 12\%, respectively in the total lipid (TL) of fresh nematodes (average for the three isolates). Levels of unsaturation (U.I.) of fresh nematodes were on average 110, 112, 113 and 152 for the TL, NL, phospholipid and free fatty acid fractions, respectively. EU17 had a slightly lower U.I than the other two strains, despite its more northern origin. Changes in fatty acid composition due to storage were most significant in the NL fraction. The U.I. for the NL fraction increased during storage, suggesting a preferential use of saturated fatty acids. (C) 1999 Elsevier Science Inc. All rights reserved.
\end{abstract}

Keywords: Entomopathogenic nematodes; Gas chromatography; Phospholipids; Neutral lipids; Free fatty acids

\section{Introduction}

The entomopathogenic nematodes of the genera Steinernema and Heterorhabditis have a symbiotic relationship with insect pathogenic bacteria Xenorhabdus and Photorhabdus, respectively. The life cycle of the nematodes, in common with that of many nematode parasites of plants and vertebrates, includes a free-living infective juvenile (IJ) whose role is transmission to a new host. Insect parasitic nematodes are commercially exploited for the biological control of several insect pests. Nematodes are produced in fermenters or in solid media and the IJs are formulated and sold for inundative application against insect pests. Steinernema sp. are less costly to produce and can survive long-term storage better than Heterorhabditis sp. However, their efficacy against certain target insects is not as good as that of Heterorhabditis [16,8,15]. For example, isolates of the North West European type of Heterorhabditis are very effective against black vine weevil

\footnotetext{
* Corresponding author. Tel.: + 353-1-6285222, ext. 3136; fax: $+353-1-7083845$

E-mail address: paulus.f.fitters@may.ie. (P.F.L. Fitters)
}

(Otiorhynchus sulcatus) and are produced in Europe for that purpose, although there is a need for more coldtolerant strains.

The total amount of lipid present in nematodes varies between 1 and 43\% [1,2] depending on their life style and habitat. Infective juveniles of Steinernema and Heterorhabditis have high levels of lipids ranging between 32 and $43 \%$ of total body weight [26,1]. These high lipid levels provide the non-feeding IJs with the energy necessary for host finding or to persist in soil when hosts are unavailable. Shelf life of commercially produced nematodes is also dependent on the amount of energy reserves stored and the rate of utilisation during storage.

Most of the phospholipids (PL) found in nematodes are probably structural components, particularly cell membranes, while neutral lipid (NL) and free fatty acids (FFA) serve mainly as energy reserves in aerobic species [2,3]. The degree of unsaturation and chain length of fatty acids (FAs) are of important biological significance for the organism. Unsaturation, i.e. the presence of double bonds, is used to enhance fluidity of FAs. The greater the degree of unsaturation, the lower the melting point of the fatty acid. For cell membranes 
this means that they remain in a functional state even at low temperatures [29]. This is particularly important for animals living at low temperature in which unsaturated fatty acids predominate over saturated ones [29]. The degree of unsaturation of FAs of the NL and FFA fractions is also important, since more energy is yielded by oxidation of saturated than of unsaturated FAs.

Fatty acids in insect parasitic nematodes have been studied by a number of researchers [26,27,30,6,$1,13,21,22]$, but most of these studies focussed on Steinernema spp. For Heterorhabditis spp., only the fatty acid composition of the total lipid (TL) has been analysed $[26,27]$. There is intraspecific variation in several important attributes of insect parasitic nematodes. For example, within the North West European (NWE) group of Heterorhabditis, there is much variation in persistence [5]. In the present study, we determined the fatty acid composition of three geographically diverse isolates of Heterorhabditis. This will, for the first time, provide detailed information on the NL, PL and FFA of Heterorhabditis, and assess the degree of intraspecific variation in lipid composition of these nematodes. Isolates UK211 and HF85 from the south of England and The Netherlands, respectively, were chosen because of their commercial relevance and inclusion in other studies. We included an isolate from Estonia, EU17, to see if this isolate is different in fatty acid composition due to its more northern origin. Estonia experiences severe winters and is at the northern fringe of the currently known distribution of the NWE type of Heterorhabditis [10]. For two of the isolates (UK211 and HF85), the analysis was performed both on newly emerged and on 5 week-old IJs. The information obtained by this study might elucidate differences in survival within Heterorhabditis spp. and between Heterorhabditis and Steinernema spp.

\section{Materials and methods}

\subsection{Nematodes culturing and storage}

The three Heterorhabditis isolates used, UK211, HF85 and EU17, all belong to the NWE group [28]. The isolates originate from the South Coast of England (Dr W. M. Hominick, CABI Bioscience, Egham, UK), the Flevopolder in The Netherlands (Dr P. Westerman, Van Hall Institute, Leeuwarden, The Netherlands) and near Tallinn in Estonia, respectively. All nematodes were reared in late instar larvae of the greater wax moth, Galleria mellonella (The Mealsworm Co., Sheffield, UK), at $20^{\circ} \mathrm{C}$. After harvesting, the IJs were washed three times by sedimentation in tap water. The IJs that were used for lipid analysis after 5 weeks were stored in tap water held in plastic culture boxes $(15 \times$ $11 \times 6 \mathrm{~cm})$ at a concentration of $1000 \mathrm{IJs} \mathrm{ml}^{-1}(200 \mathrm{ml}$ per box) and aerated by shaking daily. Prior to the lipid analysis, the IJs were washed by sedimentation and live nematodes were obtained by allowing them to pass through a $34-\mu \mathrm{m}$ sieve overnight. The resulting IJs were concentrated in $1.8 \mathrm{ml}$ cryogenic vials and stored in liquid nitrogen. For the newly emerged IJs, three replicates of 100000 nematodes were analysed and for the 5 week-old IJs $3 \times 300000$ nematodes were analysed (due to their expected lower lipid content).

\subsection{Analysis of fatty acid composition}

The technique used to isolate lipids was based on that of Christie [4] and modified by Patel and Wright $[21,22]$. In brief, nematodes were homogenised by sonication and freeze dried. Lipids were extracted with chloroform and contaminants removed with a $0.04 \%$ $\mathrm{CaCl}_{2}$ solution. Absolute ethanol was added to make a single phase of the chloroform layer with any remaining upper phase. The solvents were removed by rotary film evaporation and the percentage total lipid (of dry weight) determined.

A fraction of the extracted lipid $(10 \%)$ was put aside as the TL sample, and the rest was separated into different lipid classes by solid phase chromatography $\left(\mathrm{NH}_{2}\right.$-aminopropyl, $500 \mathrm{mg}, 3 \mathrm{ml}$; Bond Elut ${ }^{\circledR}$, International Sorbent Technology Ltd, Mid Glamorgan, UK). Lipid mixtures were dissolved in less than $0.5 \mathrm{ml}$ chloroform and applied to the columns. Each lipid fraction was eluted with $2 \times 2 \mathrm{ml}$ of solvent: the neutral lipids were eluted with chloroform:propan-2-ol (2:1), free fatty acids with acetic acid in diethylether $(2 \% \mathrm{v} / \mathrm{v})$ and the column was finally washed with methanol to elute the non-acidic phospholipids. The samples were dried by rotary film evaporation and their dry weight determined.

The lipid samples were saponified and converted to fatty acid methyl esters (FAMEs) using a mixture of toluene and $1 \%(\mathrm{v} / \mathrm{v})$ sulphuric acid in methanol (1:2 $\mathrm{v} / \mathrm{v})$. The dry FAMEs were dissolved in a known volume of hexane and analyzed by gas-liquid chromatography (GLC) using a Varian 6000 equipped with a capillary column (Carbowax EconoCa ${ }^{\mathrm{TM}} 30 \mathrm{~m} \times 0.32$ $\mathrm{mm}$ internal diameter, $0.25 \mu \mathrm{m}$ film thickness, Altech Associates, Lancashire, U.K.) and a flame ionization detector $\left(270^{\circ} \mathrm{C}\right)$. Injections were made in split mode (50:1) with $\mathrm{N}_{2}$ as the carrier gas. The temperature program was isothermal at $100^{\circ} \mathrm{C}$ for $2 \mathrm{~min}, 10^{\circ} \mathrm{C}$ $\min ^{-1}$ to $160^{\circ} \mathrm{C}$ and $2^{\circ} \mathrm{C} \min ^{-1}$ to $235^{\circ} \mathrm{C}$ and held for 1 min. GLC peak areas were quantified using a Varian 401 Vista integrator. FAMEs were identified by reference to authentic standards and by using the 'equivalent chain-length' method [4]. Fatty acid compositions were expressed as mol percentages. Unsaturation indices (U.I.) are expressed as cumulative percentage fatty acid $\times$ number of double bonds. 


\subsection{Statistical analysis}

The fatty acid data were analyzed using CSS Statistica (StatSoft Inc., Tulsa, OK, USA). Proportion data were subject to arcsine square root transformation before MANOVA and if appropriate followed by Duncan's multiple range test $(P<0.05)$.

\section{Results}

\subsection{Lipid content of fresh nematodes}

The TL content of freshly harvested (week 0) Heterorhabditis IJs was 34-43\% dry weight (Table 1). Total lipid as $\%$ of dry weight did not differ significantly $(P>0.05)$ between the three isolates. However, HF85 had significantly $(P<0.05)$ less TL per infective juvenile than either UK211 or EU17. The percentage composition of the major lipid classes differed between isolates (Table 1): NL comprised $91-94 \%$ of the TL in UK211 and EU17, but only 70\% in HF85. HF85 had correspondingly higher levels of PL than the other two isolates $(14 \%$ of TL compared with $2 \%$ for each of the other two isolates).

\subsection{Fatty acid composition of total lipid, neutral lipids,} phospholipids and free fatty acids of fresh nematodes

The major fatty acid of the total lipid fraction of freshly harvested nematodes was oleic (C18:1n-9), representing approximately half of the TL (Table 2). Palmitic (C16:0) and linoleic acids (C18:2n-6) each accounted for a further $10-15 \%$ of TL (Table 2). The fatty acid composition of the NL (Table 3), which accounts for $70-94 \%$ of TL, was similar to that of the TL, with oleic, linoleic and palmitic acids predominating.
For the PL fraction (Table 4), higher levels of FAs with a chain length of 20 or more were found compared with the NL fraction. Long chain FAs comprised 9$12 \%$ of the PL compared with a maximum of $6 \%$ in the NL fraction.

The composition of the free fatty acid fraction (Table 5) differed from that of the NL. While oleic acid was the dominant fatty acid, it represented only $20-28 \%$ of the fraction. There was a proportionately greater representation of other FAs: the percentage of C16:4 was 3 -5-fold higher than in the NL, and that of C20:4n-6 was 6-7-fold higher than in the NL. The FFA fraction had the highest unsaturation index (U.I.): 140-161 compared with a maximum of 120 in either NL or PL fractions (Tables 3-5). The high U.I. of the FFA can be explained by the higher representation of poly-unsaturated fatty acids, which accounted for $39-46 \%$ of the FFA fraction compared with a maximum of $29 \%$ in either of the other two fractions.

The fatty acid composition of the three Heterorhabditis isolates was similar, with only small differences. For instance, the TL fraction of EU17 had a significantly $(P<0.05)$ lower level of C16:3n-3 compared with the other two isolates and a higher level of $\mathrm{C} 16: 0$ (compared with HF85) and C20:1n-9 (compared with UK211) (Table 2). The FAs of EU17 were more saturated than the FAs in UK211 and HF85, as shown by the lower unsaturation index in all fractions measured (Tables 2-5).

\subsection{Lipid content and fatty acid composition after storage}

After 5 weeks storage at $20^{\circ} \mathrm{C}, \mathrm{HF} 85$ had lost $57 \%$ of its total lipid, and UK211 had lost 94\% (Table 1). This decline in lipid content was mainly due to a decrease in NL: HF85 had lost $48 \%$ of its NL after 5 weeks, and UK211 had lost 94\%.

Table 1

Total IJ dry weight, total lipid dry weight, percentage total lipid and neutral lipid, phospholipid and free fatty acid as a percentage of total lipid, of IJs of Heterorhabditis isolates HF85, UK211 and EU17 freshly harvested and after 5 weeks storage at $20^{\circ} \mathrm{C}^{\mathrm{a}}$

\begin{tabular}{|c|c|c|c|c|c|c|}
\hline Isolate and age & $\begin{array}{l}\text { Dry weight } \\
(\mathrm{ng} \mathrm{IJ}-1)\end{array}$ & $\begin{array}{l}\text { Total lipid dry weight } \\
(\mathrm{ng} \mathrm{IJ}-1)\end{array}$ & $\begin{array}{l}\text { Total lipid } \\
(\%)\end{array}$ & $\begin{array}{l}\text { Neutral lipid } \\
(\%)\end{array}$ & $\begin{array}{l}\text { Phospholipid } \\
(\%)\end{array}$ & $\begin{array}{l}\text { Free fatty acid } \\
(\%)\end{array}$ \\
\hline \multicolumn{7}{|l|}{ HF85 } \\
\hline 0 weeks & 166.8 bA (11.1) & $61.1 \mathrm{bA}(2.0)$ & $36.6 \mathrm{aA}(1.7)$ & 69.6 bA (1.9) & 13.9 aA (6.3) & $6.5 \mathrm{aA}(4.6)$ \\
\hline 5 weeks & 132.9 A (3.8) & 26.4 B (1.7) & 19.9 B (0.9) & 82.2 B (3.1) & 8.0 A (1.4) & 9.8 B (2.1) \\
\hline \multicolumn{7}{|l|}{$U K 211$} \\
\hline 0 weeks & $181.2 \mathrm{abA}(14.6)$ & $77.4 \mathrm{aA}(2.5)$ & $42.7 \mathrm{aA}(3.2)$ & $91.1 \mathrm{aA}(7.7)$ & $1.6 \mathrm{bA}(1.1)$ & $7.3 \mathrm{aA}(6.7)$ \\
\hline 5 weeks & 92.7 B (2.9) & 4.8 B (1.0) & 5.2 B (1.1) & 46.5 B (7.2) & $3.2 \mathrm{~A}(4.5)$ & $50.3 \mathrm{~B}(4.7)$ \\
\hline \multicolumn{7}{|l|}{ EU17 } \\
\hline 0 weeks & 233.0 a (14.3) & 80.2 a (1.7) & 34.4 a (4.9) & 93.9 a (1.6) & $2.0 \mathrm{ab}(1.4)$ & 4.2 a $(3.0)$ \\
\hline
\end{tabular}

a Mean of three replicates (SE). Within a column, values accompanied by the same letter are not significantly different $(P>0.05)$. Lower case: between isolates at week 0 (ANOVA); upper case: between weeks for each isolate ( $t$-test). 
Table 2

Fatty acid composition $(\% \pm \mathrm{SE})$ of total lipids from infective juveniles of Heterorhabditis isolates UK211, HF85 and EU17, freshly harvested and after 5 weeks storage in water at $20^{\circ} \mathrm{C}^{\text {a }}$

\begin{tabular}{|c|c|c|c|c|c|}
\hline \multirow{2}{*}{$\begin{array}{l}\text { Storage time: } \\
\text { Isolate: } \\
\text { Fatty acid: }\end{array}$} & \multicolumn{3}{|l|}{0 Weeks } & \multicolumn{2}{|l|}{5 Weeks } \\
\hline & UK211 & HF85 & EU17 & UK211 & HF85 \\
\hline 14:0 & $0.5 \pm 0.0$ & $0.6 \pm 0.0$ & n.d. & $0.6 \pm 0.1$ & $0.7 \pm 0.0$ \\
\hline $14: 1$ & $1.4 \pm 0.1$ & $1.4 \pm 0.1$ & $0.6 \pm 0.3$ & $1.8 \pm 0.1$ & $2.2 \pm 0.1$ \\
\hline $16: 0$ & $10.4 \pm 0.4 \mathrm{ab}$ & $11.7 \pm 0.1 \mathrm{~b}$ & $15.3 \pm 1.8 \mathrm{a}$ & $4.9 \pm 0.1 \mathrm{~d}$ & $6.7 \pm 0.2 \mathrm{c}$ \\
\hline $16: 3 n-3$ & $1.2 \pm 0.0 \mathrm{a}$ & $1.1 \pm 0.0 \mathrm{a}$ & $0.3 \pm 0.2 \mathrm{~b}$ & $1.2 \pm 0.0 \mathrm{a}$ & $1.5 \pm 0.1 \mathrm{a}$ \\
\hline $16: 4$ & $1.6 \pm 0.1 \mathrm{~b}$ & $1.8 \pm 0.1 \mathrm{~b}$ & $1.2 \pm 0.1 \mathrm{~b}$ & $4.4 \pm 0.5 \mathrm{a}$ & $2.2 \pm 0.2 b$ \\
\hline $18: 0$ & $0.7 \pm 0.5 \mathrm{~b}$ & $0.5 \pm 0.4 \mathrm{~b}$ & $3.0 \pm 0.5 \mathrm{~b}$ & $8.2 \pm 0.2 \mathrm{a}$ & $0.8 \pm 0.6 \mathrm{~b}$ \\
\hline $18: \ln -9$ & $49.1 \pm 0.5 \mathrm{a}$ & $52.9 \pm 0.2 \mathrm{a}$ & $50.3 \pm 1.0 \mathrm{ab}$ & $38.2 \pm 0.1 \mathrm{c}$ & $46.2 \pm 0.8 \mathrm{~b}$ \\
\hline $18: 2 n-6$ & $13.9 \pm 0.4 b$ & $11.9 \pm 0.1 \mathrm{c}$ & $11.0 \pm 0.7 \mathrm{c}$ & $14.3 \pm 0.0 \mathrm{~b}$ & $18.8 \pm 0.2 \mathrm{a}$ \\
\hline $18: 3 n-3$ & $2.2 \pm 0.1 \mathrm{a}$ & $1.5 \pm 0.1 \mathrm{ab}$ & $1.6 \pm 0.1 \mathrm{bc}$ & $1.2 \pm 0.1 \mathrm{c}$ & $1.6 \pm 0.1 \mathrm{bc}$ \\
\hline $20: 1 n-9$ & $2.8 \pm 0.1 \mathrm{~b}$ & $2.7 \pm 0.1 \mathrm{ab}$ & $3.9 \pm 0.5 \mathrm{a}$ & $2.0 \pm 0.2 b$ & $1.7 \pm 0.1 \mathrm{~b}$ \\
\hline Saturated & 11.6 & 12.08 & 18.3 & 13.7 & 8.2 \\
\hline Monoene & 61.1 & 64.6 & 61.1 & 46.4 & 57.3 \\
\hline Polyene & 22.1 & 19.1 & 15.7 & 35 & 29.5 \\
\hline U.I. & 115.9 & 112.8 & 99.8 & 147.0 & 131.4 \\
\hline ng/nematode & $77.4 \pm 2.5$ & $61.1 \pm 2.0$ & $80.2 \pm 1.7$ & $4.8 \pm 1.0$ & $26.4 \pm 1.7$ \\
\hline
\end{tabular}

${ }^{a}$ Unless mentioned otherwise; $n=3$; n.d. = not detectable; U.I. = unsaturation index, defined as $\Sigma(\%$ of fatty acid $\times$ number of double bonds $)$. Within rows, same or no letters indicate no significant difference (MANOVA, Duncan's multiple range test, $P<0.05$ ).

The fatty acid composition of stored IJs differed from that of the fresh ones. For both isolates, the percentage of palmitic acid and oleic acid in the TL decreased significantly between week 0 and week 5 , and arachidonic acid (C20:4n-6) increased significantly $(P<0.05$; Table 2$)$. The change in fatty acid composition of the TL was more marked for UK211 than for HF85; additional significant changes detected for UK211 were a decrease in the percentage of $16: 1 \mathrm{n}-7$ and $\mathrm{C} 18: 3 \mathrm{n}-3$ and an increase in C16:4, stearic acid (C18:0), C20:2 and C20:4n-6.

Changes in the NL fraction (Table 3) were similar to those in the TL. There was a significant decrease in the percentage of palmitic and a (non-significant) decrease in oleic acid. Significant increases were found in the percentage of the C20 polyunsaturated FAs (C20:2, C20:4n-6 and C20:5n-3 (eicosapentaenoic acid; not significant for $\mathrm{HF} 85)$ ).

A significant decrease in the proportion of palmitic acid (C16:0) was again detected in the FFA fraction (Table 5), a significant increase in C18:0 was found for UK211.

Starving the IJs for 5 weeks had little effect on fatty acid composition of the phospholipid fraction. Two notable significant changes were the decrease in palmitic acid (C16:0) of $\mathrm{HF} 85$ and a decrease in C20:1n-9 for UK211.

The level of unsaturation increased between week 0 and week 5 for the TL and NL fractions, but remained largely unchanged for the PL and FFA fractions.
Differences between UK211 and HF85 were more marked in stored than in fresh nematodes. In week 0 , the TL of HF85 and UK211 differed significantly with respect to only one fatty acid (linoleic), while the two isolates differed significantly with respect to 8 FAs after 5 weeks (Table 2). Similarly, in the NL fraction more differences were detected between isolates following storage.

\section{Discussion}

The $43 \%$ lipid content recorded for Heterorhabditis UK211 is amongst the highest lipid contents recorded for hatched stages of any nematode species [2]. The lipid content of the three isolates, at $34-43 \%$ dry weight, provides further evidence that entomopathogenic nematodes tend to have rather high lipid content. Other reported values for Heterorhabditis and Steinernema span a similar range: $H$. megidis and $H$. bacteriophora contained 36 and 38\% lipid, respectively [26] while Steinernema spp. ranged between $32 \%$ and $39 \%$ $[26,23]$ with a maximum of $43 \%$ recorded for Steinernema riobravis grown in G. mellonella [1]. A high lipid content is necessary for the non-feeding IJs of entomopathogenic nematodes to survive in soil or storage, until they encounter a new host insect.

Only one other study has looked at the fatty acid composition of Heterorhabditis spp. [26] and that 
looked only at TL of $H$. megidis and H. bacteriophora. The fatty acid profile of total lipids presented here differs in several respects from the profiles presented for $H$. bacteriophora and especially for $H$. megidis [26]. In particular, unsaturated $\mathrm{C} 16 \mathrm{FAs}$, which represented $7-11 \%$ of TL in the present study, were not detected by Selvan et al. [26], and longer chain FAs (C22 and C24) which represented $20 \%$ of the FAs in the total lipids of $H$. megidis and $11 \%$ in $H$. bacteriophora in the Selvan et al. [26] study, were absent in the present analysis. The NWE group of Heterorhabditis isolates analysed here had a preponderance of unsaturated FAs; more than $80 \%$ of the TL FAs were unsaturated, a pattern typical of most nematodes [12,17] including Steinernema spp. [1,21], while Selvan et al. [26] reported approximately $60 \%$ unsaturated FAs for Heterorhabditis. While it is possible that strain or species differences contribute to the differences between the two studies, this is unlikely to be the full explanation, as four species of Steinernema analysed by Selvan et al. [26] also had unexpectedly low levels of unsaturation in comparison with the data of Patel and Wright [21].

The major fatty acid of the TL fraction was oleic (C18:1n-9), with palmitic (C16:0) and linoleic acids (C18:2n-6) each accounting for a further 10\% of TL. These FAs are also predominant in $H$. bacteriophora [26] and in most studies on Steinernema sp. $[30,6,1,21,22]$, together with $\mathrm{C} 18: 0$ in some cases $[6,1]$.
However, stored energy reserves in nematodes do not always comprise these three FAs. In some plant parasitic nematodes, C20:1 and C20:4 may predominate $[12,17]$.

Neutral lipids form the major energy store for the non-feeding infective stage of entomopathogenic and other parasitic nematodes. Where it has been investigated, there is evidence that certain FAs are utilised preferentially $[25,27,19,21]$. The proportion of 16:0, C16:1n-7 and 18:1n-9 in the NL fraction decreased during 5-weeks storage of UK211 and HF85, indicating preferential utilisation of these FAs, particularly palmitic acid. Palmitic acid accounted for $10-12 \%$ of the NL fraction of fresh nematodes, but the percentage representation was halved after storage and the decrease was significant for both isolates. The preferential utilisation of saturated FAs such as palmitic, rather than unsaturated ones, is also indicated by the increase in U.I. following storage. This increase in unsaturation levels following storage was also observed for entomopathogenic nematodes by Selvan et al. [27] and Patel and Wright [21]. Biological oxidation of saturated FAs yields more energy than oxidation of unsaturated FAs [29]. Preferential utilisation of high-energy yielding FAs by IJs means that the remaining store of FAs will be of an incrementally lower value, and thus a given unit of triglyceride measured in starved nematodes is expected to be of lower energetic value than in fresh nematodes.

Table 3

Fatty acid composition $(\% \pm \mathrm{SE})$ of neutral lipids from infective juveniles of Heterorhabditis isolates UK211, HF85 and EU17, freshly harvested and after 5 weeks storage in water at $20^{\circ} \mathrm{C}^{\text {a }}$

\begin{tabular}{|c|c|c|c|c|c|}
\hline \multirow{2}{*}{$\begin{array}{l}\text { Storage time: } \\
\text { Isolate: } \\
\text { Fatty acid: }\end{array}$} & \multicolumn{3}{|l|}{0 Weeks } & \multicolumn{2}{|l|}{5 Weeks } \\
\hline & UK211 & HF85 & EU17 & UK211 & HF85 \\
\hline 14:0 & $0.5 \pm 0.0$ & $0.5 \pm 0.0$ & $0.5 \pm 0.0$ & $0.7 \pm 0.0$ & $0.6 \pm 0.1$ \\
\hline $14: 1$ & $1.4 \pm 0.0 \mathrm{ab}$ & $1.4 \pm 0.1 \mathrm{~b}$ & $1.1 \pm 0.0 \mathrm{~b}$ & $1.9 \pm 0.1 \mathrm{a}$ & $2.0 \pm 0.2 \mathrm{a}$ \\
\hline $16: 0$ & $10.3 \pm 0.3 \mathrm{a}$ & $11.7 \pm 0.2 \mathrm{a}$ & $11.5 \pm 0.0 \mathrm{a}$ & $4.9 \pm 0.1 \mathrm{c}$ & $6.8 \pm 0.3 \mathrm{~b}$ \\
\hline $16: 3 n-3$ & $1.3 \pm 0.0 \mathrm{ab}$ & $1.4 \pm 0.2 \mathrm{a}$ & $0.8 \pm 0 . .0 \mathrm{~b}$ & $1.3 \pm 0.0 \mathrm{ab}$ & $1.4 \pm 0.1 \mathrm{a}$ \\
\hline $16: 4$ & $1.3 \pm 0.0 \mathrm{~b}$ & $1.3 \pm 0.1 \mathrm{~b}$ & $1.3 \pm 0.1 \mathrm{~b}$ & $1.8 \pm 0.0 \mathrm{a}$ & $1.2 \pm 0.0 \mathrm{~b}$ \\
\hline 18:0 & n.d. & n.d. & n.d. & $2.9 \pm 0.1$ & n. $\bar{d}$ \\
\hline $18: 1 n-9$ & $49.7 \pm 1.4$ & $54.5 \pm 0.8$ & $52.0 \pm 1.2$ & $48.5 \pm 0.7$ & $48.7 \pm 1.3$ \\
\hline $18: 2 n-6$ & $13.7 \pm 0.3 b$ & $11.9 \pm 0.2 \mathrm{c}$ & $12.7 \pm 0.5 b c$ & $14.1 \pm 0.3 b$ & $19.8 \pm 0.2 \mathrm{a}$ \\
\hline $18: 3 n-3$ & $2.0 \pm 0.1$ & $1.6 \pm 0.1$ & $1.6 \pm 0.2$ & $1.8 \pm 0.2$ & $1.6 \pm 0.1$ \\
\hline $20: 1 n-9$ & $2.9 \pm 0.3$ & $2.4 \pm 0.0$ & $2.6 \pm 0.2$ & $2.9 \pm 0.2$ & $1.9 \pm 0.1$ \\
\hline $20: 5 n-3$ & $0.3 \pm 0.0 \mathrm{~b}$ & $0.3 \pm 0.0 \mathrm{~b}$ & $0.1 \pm 0.1 \mathrm{c}$ & $1.0 \pm 0.0 \mathrm{a}$ & $0.6 \pm 0.0 \mathrm{~b}$ \\
\hline Saturated & 10.8 & 12.2 & 12.0 & 8.5 & 7.4 \\
\hline Monoene & 61.9 & 66.4 & 63.7 & 58.3 & 60.1 \\
\hline Polyene & 21.0 & 18.6 & 18.5 & 27.3 & 28.7 \\
\hline U.I. & 114.1 & 113.5 & 109.0 & 134.0 & 130.7 \\
\hline ng/nematode & $70.2 \pm 1.5$ & $42.4 \pm 0.9$ & $75.3 \pm 2.9$ & $2.4 \pm 0.7$ & $21.7 \pm 1.8$ \\
\hline
\end{tabular}

${ }^{a} \mathrm{n}=3$; n.d. = not detectable; U.I. = unsaturation index defined as $\Sigma(\%$ of fatty acid $\times$ number of double bonds $)$. Within rows, same or no letters indicate no significant difference (MANOVA, Duncan's multiple range test, $P<0.05$ ). 
Table 4

Fatty acid composition ( $\% \pm \mathrm{SE})$ of the phospholipids of infective juveniles of Heterorhabditis isolates UK211, HF85 and EU17, freshly harvested and after 5 weeks storage in water at $20^{\circ} \mathrm{C}^{\mathrm{a}}$

\begin{tabular}{|c|c|c|c|c|c|}
\hline \multirow{2}{*}{$\begin{array}{l}\text { Storage time:: } \\
\text { Isolate: } \\
\text { Fatty acid: }\end{array}$} & \multicolumn{3}{|l|}{0 Weeks } & \multicolumn{2}{|l|}{5 Weeks } \\
\hline & UK211 & HF85 & EU17 & UK211 & HF85 \\
\hline 14:0 & n.d. & $1.0 \pm 0.2$ & n.d. & $1.4 \pm 0.6$ & n.d. \\
\hline $14: 1$ & $0.8 \pm 0.3$ & $1.4 \pm 0.2$ & n.d. & $1.1 \pm 0.4$ & $1.0 \pm 0.4$ \\
\hline $16: 0$ & $8.9 \pm 0.6 \mathrm{bc}$ & $12.1 \pm 0.5 \mathrm{a}$ & $12.2 \pm 0.6 \mathrm{abc}$ & $8.9 \pm 1.1 \mathrm{abc}$ & $6.7 \pm 0.1 \mathrm{c}$ \\
\hline $16: 3 n-3$ & $1.8 \pm 0.2$ & $0.8 \pm 0.1$ & n.d & n.d. & n.d. \\
\hline $16: 4$ & $0.9 \pm 0.4$ & $1.8 \pm 0.2$ & n.d & $1.2 \pm 0.5$ & $2.2 \pm 0.5$ \\
\hline 18:0 & $8.4 \pm 1.4$ & $4.5 \pm 0.9$ & $7.0 \pm 0.6$ & $6.3 \pm 1.4$ & $6.6 \pm 1.5$ \\
\hline $18: 1 n-9$ & $33.5 \pm 4.3$ & $38.7 \pm 2.5$ & $34.6 \pm 1.2$ & $27.6 \pm 2.7$ & $36.9 \pm 3.2$ \\
\hline $18: 2 n-6$ & $15.6 \pm 0.9$ & $11.0 \pm 0.5$ & $15.4 \pm 0.6$ & $10.0 \pm 1.1$ & $15.1 \pm 1.7$ \\
\hline $18: 3 n-3$ & $2.1 \pm 0.1$ & $1.8 \pm 0.1$ & $2.2 \pm 0.2$ & $2.2 \pm 7.0$ & $2.4 \pm 0.5$ \\
\hline $20: 1 n-9$ & $3.2 \pm 0.2 \mathrm{a}$ & $2.3 \pm 0.1 \mathrm{ab}$ & $3.0 \pm 0.2 \mathrm{a}$ & $1.9 \pm 0.1 \mathrm{~b}$ & $2.2 \pm 0.2 \mathrm{ab}$ \\
\hline $20: 5 n-3$ & n.d. & $2.2 \pm 0.3$ & n.d. & $3.4 \pm 0.4$ & $2.0 \pm 0.7$ \\
\hline Saturated & 17.3 & 17.6 & 19.2 & 16.6 & 13.3 \\
\hline Monoene & 43.6 & 50.9 & 44.5 & 39.3 & 46.5 \\
\hline Polyene & 29.3 & 21.7 & 25.0 & 24.6 & 29.6 \\
\hline U.I. & 119.5 & 112.9 & 106.3 & 114.1 & 129.1 \\
\hline ng/nematode & $1.3 \pm 0.6$ & $8.6 \pm 2.5$ & $1.6 \pm 1.1$ & $0.1 \pm 0.1$ & $2.1 \pm 0.2$ \\
\hline
\end{tabular}

${ }^{\text {a }} n=3$; n.d. $=$ not detectable; U.I. = unsaturation index defined as $\Sigma(\%$ of fatty acid $\times$ number of double bonds $)$. Within rows, same or no letters indicate no significant difference (MANOVA, Duncan's multiple range test, $P<0.05$ ).

However, preferential use of certain FAs was not observed in recent work on cysts of Globodera rostochiensis and $G$. pallida; NL fractions did not differ significantly between batches of cysts stored for up to 13 years and no increase in unsaturation level was found [12].

Species of plants and micro-organisms that normally live at lower temperatures have a membrane composition that has a lower melting point, due to the incorporation of more unsaturated lipids [11]. The level of unsaturation of the PL fraction of Heterorhabditis (U.I. $=106-120)$ in the present study is much lower than of any Steinernema sp. found in the literature (U.I. $=127-208$, with an average of $177(n=12)$; range is either specifically reported or calculated from published fatty acid data [13,6,1,22]). These findings may reflect the fact that Heterorhabditis is less well adapted to low temperatures than Steinernema sp. [20,9]. The $\mathrm{PL}$ of the Heterorhabditis isolate EU17 were less rather than more unsaturated than those of the other two isolates. Thus, the hypothesis that EU17, being from a more northern region, would have a higher level of unsaturation is not supported. In a similar comparison, Patel \& Wright [22] and Jagdale and Gordan [13] found that more warm adapted species of Steinernema did not have more saturated PL. This agrees with our results that within genus, origin does not seem to affect unsaturation level.
The degree of unsaturation can be influenced by the nematode food source. Rouse et al. [24] were able to increase both lipid content (5-fold) and double the percentage of highly unsaturated FAs in the free living soil nematode Panagrellus redivivus by adding fish oil to their diet. Differences in unsaturation levels between nematodes in the present work and that of Patel and Wright $[21,22]$ are unlikely to be caused by food source since the IJs of the entomopathogenic nematodes were in both cases reared in G. mellonella larvae obtained from the same source. Within the Heterorhabditis sp. in this work no obvious differences in FAs were found. However, it is possible that when these nematodes feed on different indigenous hosts in their natural environments, there would be larger differences in their FA composition. Another source of variation could be the bacterial symbiont of the nematodes. Entomopathogenic nematodes feed on insect tissues partially digested by their bacterial symbiont, and also ingest cells of the symbiont. Thus, differences in lipid composition may partly reflect differences in chemical composition of the bacteria. However, Photorhabdus luminescens, the bacterial symbiont of $H$. megidis had more unsaturated FAs than Xenorhabdus nematophilus, the symbiont of $S$. carpocapsae grown on the same artificial medium [7,14]. Therefore, we conclude that differences in the unsaturation level detected between the nematodes are unlikely to be due to the bacterial element of the diet. Apart 
from the effect of food source/diet on the fatty acid content, there is also evidence that IJs of Steinernema sp. are capable of in vivo synthesis of polyene fatty acids [6].

The fatty acid composition of the PL fraction remained largely unchanged following five weeks storage. This, however, does not mean that the Heterorhabditis isolates used here are not capable of modifying their membrane lipids. Patel and Wright [22] reported a dramatic (7-30-fold) increase in the proportion of C16:3n-3 in the PL of four species of Steinernema during storage over 11 weeks. However, their nematodes were stored at a higher $\left(25^{\circ} \mathrm{C}\right)$ temperature than that at which they were reared $\left(20^{\circ} \mathrm{C}\right)$ and it was suggested that the change in PL composition was an adaptation to the changed conditions, or to ageing. In the present work the nematodes were stored at the temperature at which they had been cultured. It could also be that the 5-week time frame was too short to allow changes to be detected. However, Heterorhabditis IJs survive for only short periods relative to Steinernema; after five weeks storage at $20^{\circ} \mathrm{C}$, Heterorhabditis IJs would be close to the end of their life while Steinernema IJs would be still at the beginning.

The non-acidic PL fraction of UK211 and EU17 comprised only $2 \%$ dry weight of the TL, while the level of HF85 at $14 \%$ was closest to the range of four Steinernema spp., where non-acidic PL composed of
$10-13 \%$ of the lipid dry weight [22]. In nematodes, total PL generally comprise between 6 and $15 \%$ of TL [4]. Compared with the non-acidic PL fractions in $S$. carpocapsae [22], the Heterorhabditis isolates used here have higher levels of C18 FAs and lower levels of C16 FAs. The role of these PL is not fully understood. The longer chain FAs, C20 and C22, are found in higher proportions in the PL fraction compared with the NL and FFA fraction in Steinernema sp. [21,22], and are most likely structural components of membranes. In the present work, similar levels of long chain FAs were found in both the FFA and PL fraction. It is suggested by Patel and Wright [21] that these FFAs might have other functions than structural components and can have a profound physiological effect.

Few studies have looked for intra-specific differences in lipid content and composition of nematodes. Differences were noted between the Heterorhabditis isolates in TL dry weight in fresh nematodes and the amount of lipid depleted during storage, thus changing the relative representation of the major lipid classes. Neutral lipids are considered to be the most important source of energy for IJs of entomopathogenic nematodes. Neutral lipids represented more than $90 \%$ of the total lipid of EU17 and UK211, compared with just 70\% in HF85. Although freshly harvested $\mathrm{HF} 85$ had a lower NL content than UK211, they used only $48 \%$ of the NL during 5 weeks storage while UK211 used 94\% of the NL over the same period. Lower et al. [18] noted

Table 5

Fatty acid composition $(\% \pm \mathrm{SE})$ of free fatty acids of infective juveniles of Heterorhabditis isolates UK211, HF85 and EU17, freshly harvested and after 5 weeks storage in water at $20^{\circ} \mathrm{C}^{\text {a }}$

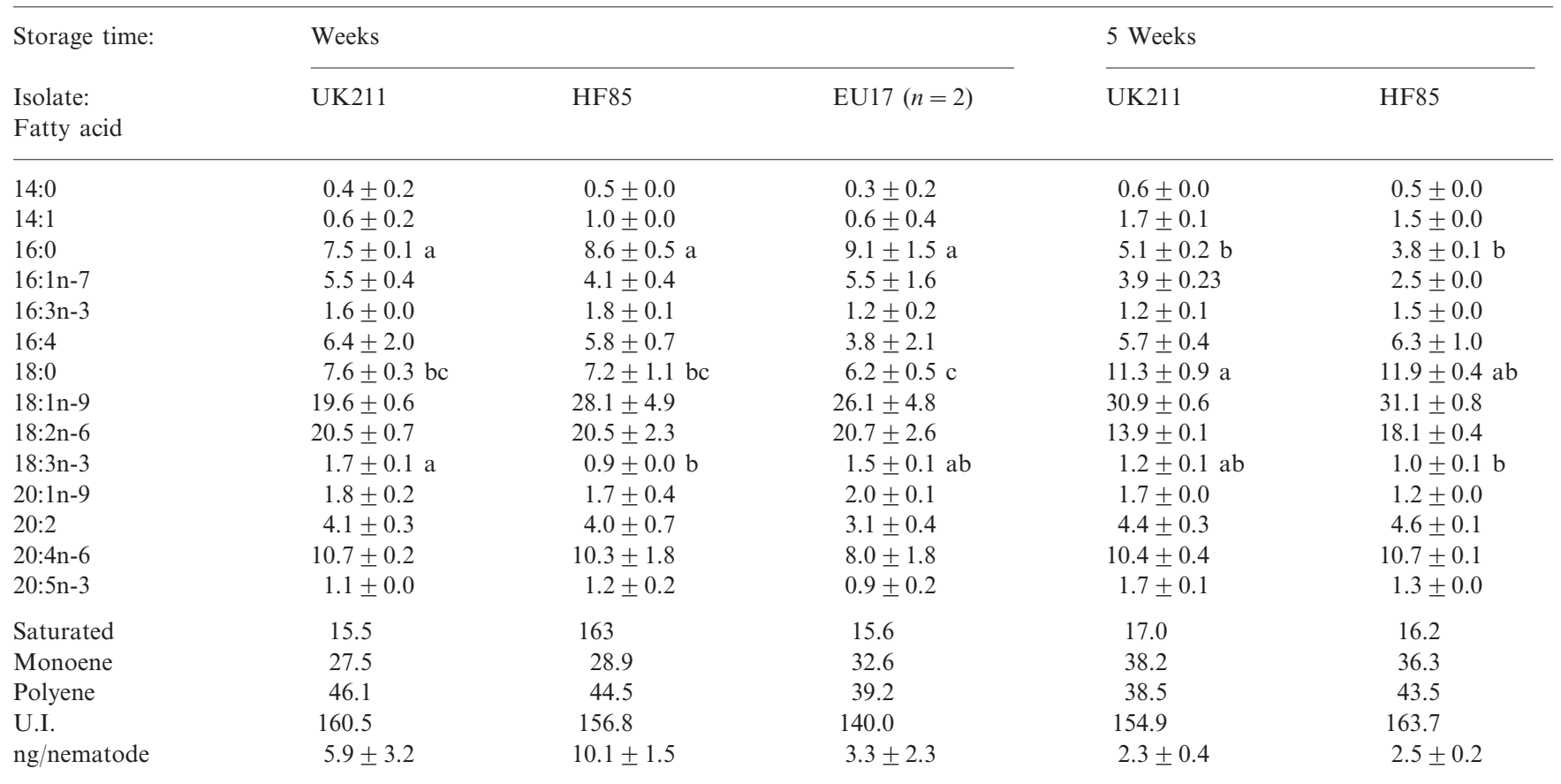

${ }^{a}$ Unless mentioned otherwise, $n=3$; n.d. = not detectable; U.I. = unsaturation index, defined as $\Sigma(\%$ of fatty acid $\times$ number of double bonds). Within rows, same or no letters indicate no significant difference (MANOVA, Duncan's multiple range test, $P<0.05$ ). 
differences in the representation of FAs in two strains of $P$. redivivus. In the present work, differences in the fatty acid composition between freshly harvested Heterorhabditis isolates were small. The occurrence of larger differences between UK211 and HF85 after storage is probably due to the fact that UK211 had utilised a higher proportion of its lipids at that time.

In conclusion, this work has shown that there are intra-specific differences between the Heterorhabditis isolates in the relative representation of the lipid fractions, but there were no obvious differences in fatty acid patterns that could be related to origin. At the inter-specific level, the lipid content and fatty acid composition of Heterorhabditis is generally similar to that of Steinernema. Such differences as do occur are relatively minor and are unlikely to make a major contribution to the greater longevity of Steinernema IJs [26]. The major differences between the two genera is that the FAs of the PL fraction of Heterorhabditis are more saturated, which is compatible with the poorer cold tolerance of these nematodes relative to Steinernema. However, Steinernema sp. may adjust the fatty acid composition of their PL in response to culture temperature [6,1]; therefore a more meaningful comparison of the PL characteristics of the two genera would include growth of the nematodes over a range of culture temperatures.

\section{Acknowledgements}

The authors would like to thank Roland A. Holz for helping with gas chromatography work. This work was carried out with the generous support of the European Environmental Research Organisation (EERO).

\section{References}

[1] Abu Hatab M, Gaugler R. Influence of growth temperature on fatty acids and phospholipids of Steinernema riobravis infective juveniles. J Therm Biol 1997;22:237-44.

[2] Barrett J, Wright DJ. Intermediary metabolism. In: Perry RN, Wright DJ, editors. The Physiology and Biochemistry of Free-Living and Plant-Parasitic Nematodes. Wallingford, Oxon, UK: CABI publishing, 1998:251-331.

[3] Chitwood DJ. Biosynthesis. In: Perry RN, Wright DJ, editors. The Physiology and Biochemistry of Free-Living and Plant-Parasitic Nematodes. Wallingford, Oxon, UK: CABI publishing, 1998:303-30.

[4] Christie WW. Gas Chromatography and Lipids. Ayr, Scotland: The Oily Press, 1989.

[5] Fitters PFL, Griffin CT. Starvation and persistence of Heterorhabditis sp. IOBC/WPRS Bull 1996;19(9):112-4.

[6] Fodor A, Dey I, Farkas T, Chitwood DJ. Effect of temperature and dietary lipids on phospholipid fatty acids and membrane fluidity in Steinernema carpocapsae. J Nematol 1994;26:278-85.

[7] Fodor E, Szallas E, Kiss Z, Fodor A, Horvath LI, Chitwood DJ, Farkas T. Composition and biophysical properties of lipids in Xenorhabdus nematophilus and Photorhabdus luminescens, symbi- otic bacteria associated with entomopathogenic nematodes. Appl Environ Microbiol 1997;63:2826-31.

[8] Georgis R, Gaugler R. The development of predictability in biological control using entomopathogenic nematodes. J Econ Entomol 1991;84:711-8.

[9] Grewal SP, Selvan S, Gaugler R. Thermal adaptation of entomopathogenic nematodes: niche breadth for infection establishment and reproduction. J Therm Biol 1994;19:245-53.

[10] Griffin CT, Dix I, Joyce SA, Burnell AM, Downes MJ. Isolation and characterisation of Heterorhabditis spp from Hungary, Estonia and Denmark. Nematology (in press).

[11] Harwood JL, Russell NJ. Lipids in Plants and Microbes. George Allen and Unwin Ltd; London, 1984.

[12] Holz RA, Wright DJ, Perry RN. The effect of long term storage on the lipid reserves and fatty acid composition of cysts and hatched juveniles of Globodera rostochiensis and G. pallida. J Helminthol 1998;72:133-41.

[13] Jagdale GB, Gordon R. Effect of temperature on the composition of fatty acids in total lipids and phospholipids of entomopathogenic nematodes. J Therm Biol 1997;22:245-51.

[14] Janse JD, Smits PH. Whole cell fatty acid patterns of Xenorhabdus species. Lett Appl Microbiol 1990;10:131-5.

[15] Kaya HK, Gaugler R. Entomopathogenic nematodes. Annu Rev Entomol 1993;38:181-206.

[16] Klein MG. Efficacy against soil-inhabiting insect pests. In: Gaugler R, Kaya HK, editors. Entomopathogenic Nematodes in Biological Control. Boca Raton, FL: CRC Press, 1990:195-214.

[17] Krusberg LR. Analysis of total lipids and fatty acids of plant-parasitic nematodes and host tissues. Comp Biochem Physiol 1967;21:83-90.

[18] Lower WL, Willett JD, Hansen EL. Selection for adaptation to increased temperatures in free-living nematodes-II. Some lipid differences in Panagrellus redivivus. Comp Biochem Physiol 1970;34:473-9.

[19] Medica DL, Sukhdeo MVK. Role of lipids in the transmission of the infective stage (L3) of Strongylus vulgaris (nematoda: Strongylida). J Parasitol 1997;83:775-9.

[20] Molyneux AS. Heterorhabditis spp. and Steinerenema (= Neoaplectana) spp.: temperature, and aspects of behavior and infectivity. Exp Parasitol 1986;62:169-80.

[21] Patel MN, Wright DJ. Fatty acid composition of neutral lipid energy reserves in infective juveniles of entomopathogenic nematodes. Comp Biochem Physiol B 1997;118:341-8.

[22] Patel MN, Wright DJ. Phospholipids and their fatty acids in infective juveniles of entomopathogenic Steinernematid nematodes. Comp Biochem Physiol B 1997;118:649-57.

[23] Patel MN, Stolinski M, Wright DJ. Neutral lipids and the assessment of infectivity in entomopathogenic nematodes: observations on four Steinernema species. Parasitology 1997;114:48996.

[24] Rouse DB, Webster CD, Radwin IA. Enhancement of the fatty acid composition of the nematode Panagrellus redivivus using three different media. J World Aquacult Soc 1992;23:898.

[25] Sivapalan P, Jenkins WR. Effects of starvation on the long-chain fatty acid composition of the free-living nematode Panagrellus redivivus. Nematologica 1999;12(99):1966.

[26] Selvan S, Gaugler R, Lewis EE. Biochemical energy reserves of entomopathogenic nematodes. J Parasitol 1993;79:167-72.

[27] Selvan S, Gaugler R, Grewal PS. Water content and fatty acid composition of infective juvenile entomopathogenic nematodes during storage. J Parasitol 1993;79:510-6.

[28] Smits PH, Groenen JTM, de Raay G. Characterization of Heterorhabditis isolates using DNA restriction polymorphism. Revue Nematol 1991;14:445-53.

[29] Stryer I. Biochemistry, 2nd edition. New York: Freeman, 1988:473.

[30] Wijbenga J, Rodgers PB. Lipid content of insect parasitic nematodes. IOBC/WPRS Bull 1994;17(3):155-8. 